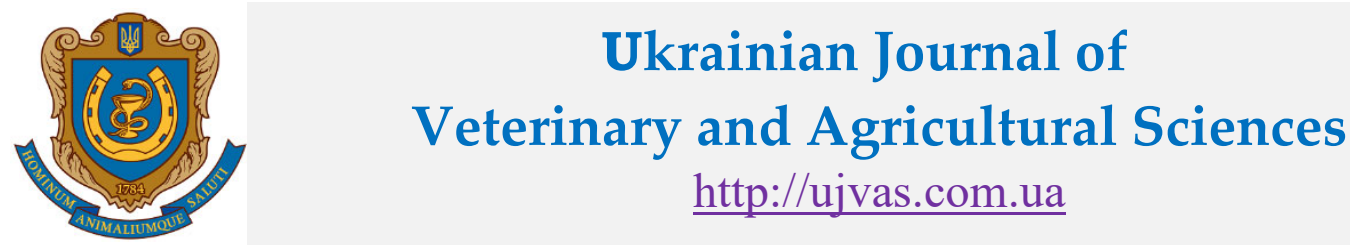

Stepan Gzhytskyi National University of Veterinary Medicine and Biotechnologies Lviv

\begin{tabular}{|c|c|c|c|}
\hline original article & UDC 615.917 & doi: $10.32718 /$ ujvas4-2.10 & lumber \\
\hline
\end{tabular}

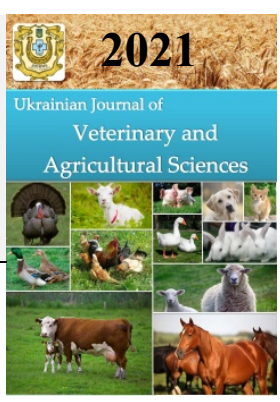

\title{
Comparison of cytotoxicity evaluation of chlorogenic acid extract between Real-time cell analysis and CCK-8 method
}

\author{
Ping Xu \\ Sumy National Agrarian University, Sumy, Ukraine \\ College of Animal Science and Veterinary Medicine, Henan Institute of Science and Technology, Xinxiang, China
}

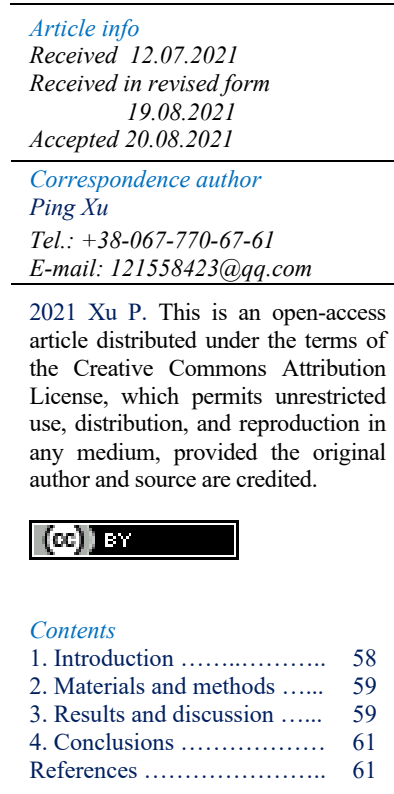

\begin{abstract}
Critical cytotoxicity evaluation of pharmaceuticals is necessary for the clinical practice of chemotherapy. To quantitatively evaluate cell viability, currently there are two main types of sensitive methods including real-time cell analysis (RTCA) and CCK-8 assay, in which RTCA records electrochemical signal changes around an incubated cell, whereas CCK-8 is based on the colorimetric method. Despite the different detection principles adopted for the cytotoxicity assessment, the comparison of the two methods in terms of the application scope is lacking. In order to compare and determine the best experimental method for the study of the toxicity of chlorogenic acid extract from taraxacum officinale on dairy cow mammary epithelial cells. The real time cell analysis (RTCA) and CCK-8 method were used to analyze the cytotoxicity of chlorogenic acid extract to BMEC and calculate its $\mathrm{IC}_{50}$. The results of the real time cell analysis method and the CCK-8 method showed that different concentrations of chlorogenic acid extract reduced the viability of dairy cow mammary epithelial cells, and the decrease was most obvious at $400 \mathrm{ug} / \mathrm{mL}$. The $\mathrm{IC}_{50}$ of the two analysis methods were 326.8 and $320.4 \mathrm{ug} / \mathrm{mL}$, respectively. In contrast, the CCK-8 method had limitations in fixed-point determination. However, the real time cell analysis method can monitor the dynamic biological response process of cell growth and proliferation in real time. Therefore, the real time cell analysis method can observe cell growth more intuitively and accurately, compensate for the shortcomings of the CCK-8 method, and it is a new experimental method for studying cytotoxicity.
\end{abstract}

Key words: inflammatory, chlorogenic acid, bovine, bovine mammary epithelial cells, cytotoxicity.

\section{Citation:}

$\mathrm{Xu}, \mathrm{P}$. (2021). Comparison of cytotoxicity evaluation of chlorogenic acid extract between Real-time cell analysis and CCK-8 method. Ukrainian Journal of Veterinary and Agricultural Sciences, 4(2), 58-61.

\section{Introduction}

Taraxacum Officinale, commonly called dandelion is herbaceous perennial belongs to the family of Asteraceae, which can be used as a medicinal material or as food. Taraxacum Officinale mainly contains various medicinal ingredients such as chlorogenic acid, caffeic acid, total flavonoids, alkaloids, polysaccharides, etc (Ling et al., 1998). It is used to treat anemia, liver cirrhosis, hepatitis and rheumatism, anti-inflammatory, anti-oxidative, anti-carcinogenic, analgesic, anti-hyperglycemic, anti-coagulatory, anticancer activities and prebiotic effects (Budzianowski, 1997; Zhu et al., 1999; Kitts \& Hu, 2005; Schütz, 2006; Hudec et al., 2007; Shi et al., 2008) which are related to its choline, sugars, saponins and chlorogenic acid and other chemical components. Chlorogenic acid is a kind of depsiptic acid belongs to phenolic compound, which can scavenge free radicals in the body and has significant antibacterial (Lou et al., 2011), anti-inflammatory (Liang \& Kitts, 2015), antioxidant (Rui et al., 2017), and anticarcinogenic (Yan et al., 2017) activities.
Gao et al. (2018) reported that CGA could be used as a potential therapeutic compound for bovine mastitis due to its anti-inflammatory role by inhibiting NF- $\mathrm{B}$ activation.

Nowadays, with the fast development and technical breakthrough in the pharmaceutical industry, there is an urgent need for the drug screening and toxicity tests. According to the analyzed signals, cell-based assays, in principle, can be classified into colorimetric assays (Fischer et al., 2003), luminogenic assays (Elisia et al., 2008), electrochemical methods (Zhou et al., 2018), cell counting methods (Braun et al., 2018), and so on. Among these methods, two conventional assays are usually applied for in vitro cellular cytotoxicity evaluation because of their easy operation and standardized readout: electrochemical methods as typified by the real-time cell analysis (RTCA) and cell counting kit- 8 (CCK-8) assay, respectively.

CCK-8 assay was established for the cytotoxic evaluation of drugs on the basis of dye labels, it has the remarkable sensitivity and operational convenience (Liao et al., 2018; Liu et al., 2018). In the CCK-8 measurement, the dye of 
WST-8 [2-(2-methoxy-4-nitrophenyl)-3-(4-nitrophenyl)-5(2,4disulfophenyl)-2H-tetrazolium, monosodium salt] was reduced by dehydrogenase in cells to form a water-soluble orange-colored product (formazan). The amount of the produced formazan dye by cellular dehydrogenases is correlated with the number of living cells. Therefore, the cell viability can be simply estimated by recording the optical density (OD) of formazan at $450 \mathrm{~nm}$ using a microplate reader. Although CCK-8 assay as a representative end point method allows convenient colorimetric readout, it limits in that each measurement can be conducted at a single time point.

Recently, RTCA holds promising potential in cellular assays because of the advantages of recording signals in a dynamic and label-free mode. In a typical run, upon cells' incubation on the arrayed gold microchips, the produced electrical impendence reflecting the physiological status of cells such as cell proliferation and viability was continuously monitored (Xu et al., 2017; Xu et al., 2018; Xu et al., 2019). Without the use of labeled dyes, RTCA permits a direct and continuous measurement of cells under physiological conditions (Otero-Gonzalez et al., 2012). Notably, as electrochemical signals were obtained, the cell number and morphology are the only determining factors in the RTCA assay, whereas other physicochemical properties like the spectroscopic absorbance of cellular components exert no influences on the analysis. Nevertheless, in the cytotoxic assay by RTCA, attention should be paid to the drug formulations that may contain electrically conductive additives.

In this study, we have directly calculated and comparedd half-maximal inhibitory concentrations $\left(\mathrm{IC}_{50}\right)$ of chlorogenic acid from the cytotoxicity evaluations by both CCK- 8 and RTCA assays.

\section{Materials and methods}

Plant material and preparation of T. Officinale chlorogenic acid extract

The whole plant of Taraxacum Officinale were collected from the campus of Sumy National Agrarian University, Sumy, Ukraine, in May 2019 and identified by Professor Li MENG, Henan Institute of Science and Technology, Xinxiang, China. The whole plants were cleaned, dried in shade for several days and pulverized in a laboratory crusher. The sample powder was extracted three times with a $70 \%$ ethanol solution at a material-to-liquid ratio of 1:20, and the three filtrates were combined to obtain an extract. Then, the extract was suspended in water. The concentrated chlorogenic acid extract of $T$. Officinale was extracted with butyl alcohol and then vacuum freeze-dried. The chlorogenic acid extract was weighed and formulated into drug solutions of different concentrations. The sample solutiong were filtered with $0.45 \mu \mathrm{m}$ filter before injection and stored at $4{ }^{\circ} \mathrm{C}$.

Cultivation and treatment of BMECS

The BMECs harvested from mid-lactation dairy cow milk were isolated by our laboratory. Briefly, the base medium for this cell is DMEM/F-12 (Gibco, USA, cat.12400024). The complete growth medium included $10 \%$ fetal bovine serum (Biological Industries, Israel, cat.04-0111A/B), DMEM/F-12, and $10 \mathrm{ng} / \mathrm{mL}$ epidermal growth factor (Sigma, USA, cat. E4127). Cells were maintained at $37{ }^{\circ} \mathrm{C}$ in an incubator containing $5 \% \mathrm{CO}_{2}$. When cells grew to $80 \%$ confluency, the cells were rinsed twice with phosphatebuffered saline (PBS, pH 7.4) and then the primary mammary epithelial cells were trypsinized with $0.25 \%$ trypsin plus
$0.02 \%$ ethylenediaminetetraacetic acid (EDTA ) and passaged.

\section{Cell Counting Kit-8 Assay of Cell Viability}

BMECs were seeded at a concentration of $1 \times 10^{4}$ cell per well in 96-well plates with eight replicates per condition. and stimulated with CGA extract $(0,12.5,25,50,100,200$, $400 \mu \mathrm{g} / \mathrm{mL}$ ) for $24 \mathrm{~h}$. At the indicated timepoint, Cell counting KIT-8 (Beijing Solarbio Science \& Technology Co., Ltd., Beijing, P. R. China, cat.CK04) solution at a medium dilution of 1:10 diluted was added to each well and the plate was incubated at $37^{\circ} \mathrm{C}$ for $3 \mathrm{~h}$. Finally, the absorbance was measured at a wavelength of $450 \mathrm{~nm}$ by a micoplate reader (Bio-Rad, Hercules, CA), and the proliferation of each groups was calcuted using the equation:

$$
[(\mathrm{AS}-\mathrm{Ab}) /(\mathrm{AC}-\mathrm{Ab})] \times 100 \% \text {. }
$$

AS: The absorbance value of the wells with cells, LTA, CCK-8;

AC: The absorbance value of the wells with cells, CCK-8;

$\mathrm{Ab}$ : The absorbance value of the wells without cells.

Real-Time Cell Assay (RTCA) of Cell Density

Totals of $4 \times 10^{4}, 2 \times 10^{4}, 1 \times 10^{4}, 5000,2500,1250$, and 625 cells per well were seeded on E-Plate, 16 plates, $150 \mu \mathrm{L}$ medium per well. Real time detection of cells was performed to optimize the optimal plate density.

Real-Time Cell Assay (RTCA) of Cell Viability

The Real-Time Cell Assay (RTCA) was used to detect the effect of different concentrations $(0,12.5,25,50,100$ $\mu \mathrm{g} / \mathrm{mL}$ ) of CGA extract on BMEC proliferation. The CI value is directly proportional to the number of cells. RTCA was determine the CI value by measuring the impedance record.

\section{Statistical analysis}

The results are expressed as means \pm SD. Statistical differences were analyzed using a t-test for independent groups. The ANOVA was performed using GraphPad Prism version 6.01 (GraphPad Software Inc., San Diego, CA, USA). Statistical significance was declared as $* \mathrm{P}<0.05, * *$ $\mathrm{P}<0.01$, and $* * * \mathrm{P}<0.001$. Each experiment was repeated at least 3 times.

\section{Results and discussion}

CCK-8 assay for cell viability

In the CCK-8 assay using BMEC cells, different concentrations of CGA extract were prepared for the cytotoxicity evaluation. As calculated by Statistical Product and Graphpad Prism 5, the $\mathrm{IC}_{50}$ value was $320.4 \mu \mathrm{g} / \mathrm{mL}$ (Fig. 1).

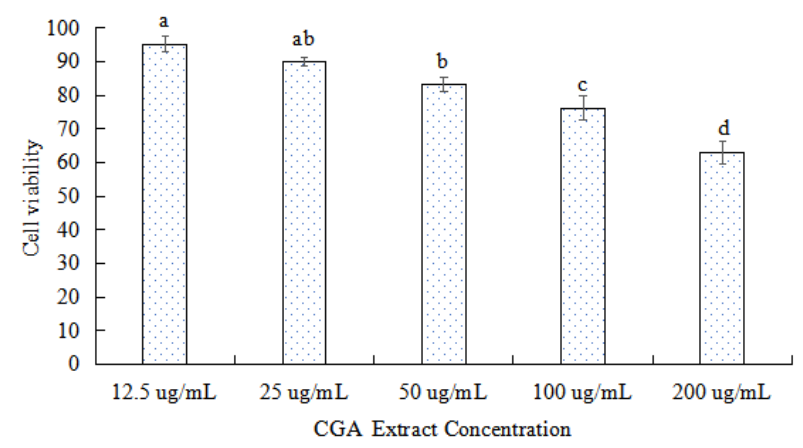

Fig. 1: Cell viability of BMEC induced by CGA extract after $24 \mathrm{~h}$ by CCK- 8 assay.

Note: Different lowercase letters indicate significant differences at $\mathrm{P}<0.05$. 
RTAC assay of BMEC Cell seeding density

Real time cell assay provides a remarkable method for real time monitoring of cell viability. The result showed that the best seeding density for the proliferation of BMECs was $1 \times 10^{4}$ cells (Fig. 2).

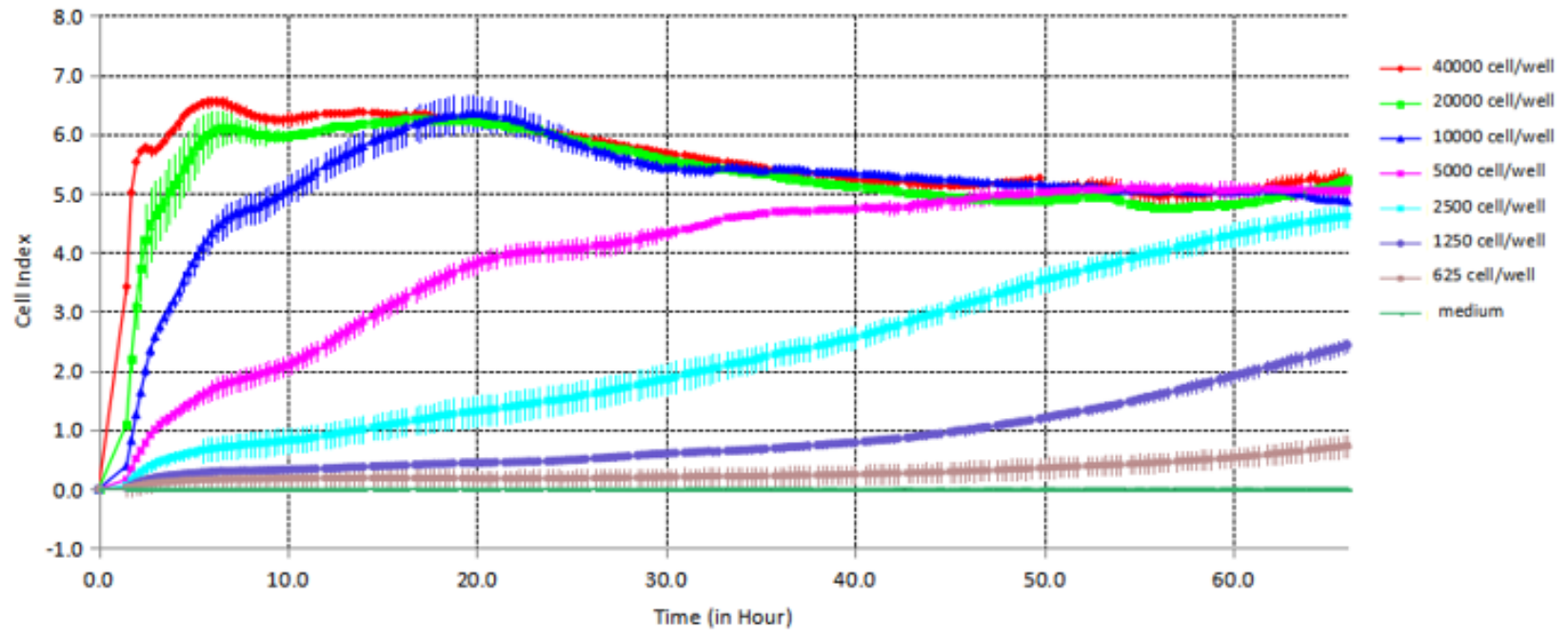

Fig. 2. Growth curves of bovine mammary epithelial cells (BMECs) with different seeding densities.

RTCA assay for cell viability

In RTCA, CGA extract of difffferent concentrations at $12.5,25,50,100$, and $200 \mu \mathrm{g} / \mathrm{mL}$ were chosen for recording the cell growth curves, and the $\mathrm{IC}_{50}$ value of $326.8 \mu \mathrm{g} / \mathrm{mL}$ was obtained, which is close to the result of the CCK-8 assay. The results showed that the cells grew exponentially before the serum-free synchronization treatment, and the growth rate of the cells became slower after the synchronization treatment, suggesting that the goal of synchronization treatment was achieved. After adding CGA, different concentrations of CGA can cause the cell viability of BMEC to decrease to varying degrees (Fig. 3).

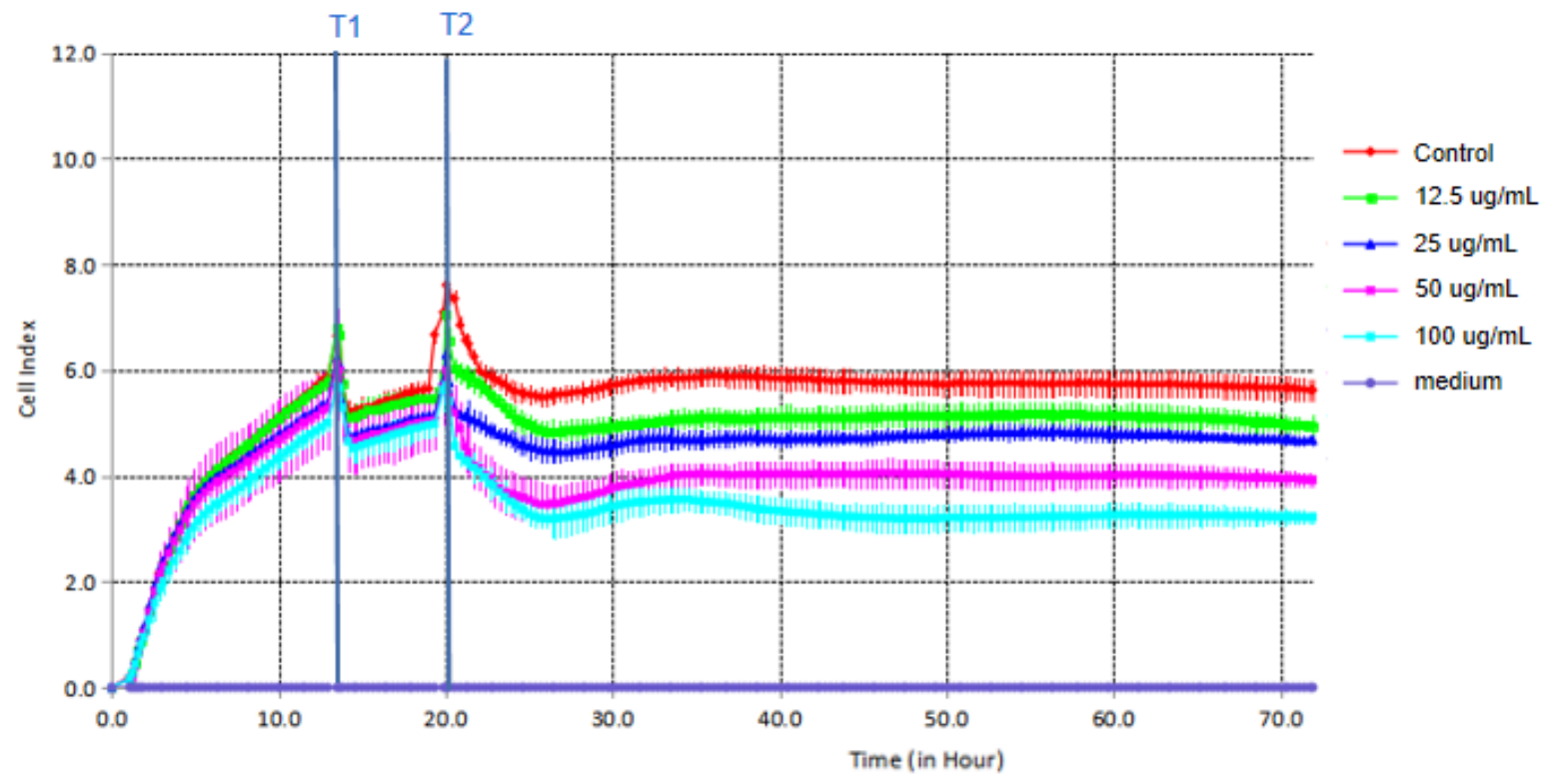

Fig. 3. Cell growth curve of BMEC induced by CGA extract by RTCA assay Note: The T1-T2 time period represents the length of synchronization.

From the perspective of the entire experimental process, RTCA can monitor the growth status of cells at different times in real time. From the cell index curve, you can intuitively see the growth of BMEC cells in the entire experimental process. The node selection for processing time can be based on the growth of cells. The basis for judging the situation is more sufficient and reliable. These results were consistent with those of both the CCK-8 and RTCA assays, which also accord well with those reported previously (Liu et al., 2016; Rezaei et al., 2016; Sriraman et al., 2016). Taken together, the data obtained by manual cell counting supported the comparison results between the CCK-8 and RTCA assays, which suggested that the applicability of these two methods should be taken into consideration in terms of cytotoxicity evaluation of the drugs. 


\section{Conclusions}

In this work, we have compared the cytotoxicity evaluation results of CGA extract between the CCK- 8 and RTCA assays. The IC50 values obtained by the two methods are 326.8 and $320.4 \mu \mathrm{g} / \mathrm{mL}$. The results indicated that the CCK8 assay as an end point method measured the optical intensity of dyes in the cell at a specific time point, of which the readout interpretation can be interfered by the colored drugs used, especially those with the absorbance peak close to 450 $\mathrm{nm}$ of dyes used for the assay. By comparison, RTCA measured the drug-added cells on the basis of electrochemical impedance and hence can give more reliable cytotoxicity evaluation results. With the fast development of new drug formulation, our studies may indicate that the preselection of methods is necessary for the drug cytotoxicity evaluation and screening to avoid the misleading results, which will be meaningful for later clinical practice.

\section{Acknowledgments}

This research was financially supported by the National Natural Science Foundation of Henan (Grant No.182300410086) and Key Scientific Research Projects of Higher Education in Henan Province (No. 20A180025).

Conflict of interest. Author does not report any financial or personal connections with other persons or organizations, which might negatively affect the contents of this publication and/or claim authorship rights to this publication.

\section{References}

Braun, K., Stürzel, C. M., Biskupek, J., Kaiser, U., Kirchhoff, F., \& Linden, M. (2018). Comparison of different cytotoxicity assays for in vitro evaluation of mesoporous silica nanoparticles. Toxicol in Vitro, 52, 214-221. doi: 10.1016/j.tiv.2018.06.019.

Budzianowski, J. (1997). Coumarins, caffeoyltartaric acids and their artifactual methyl esters from Taraxacum officinale leaves. Planta medica, 63(3), 288. doi: 10.1055/s-2006957681.

Elisia, I., Popovich, D. G., Hu, C., \& Kitts, D. D. (2008). Evaluation of Viability Assays for Anthocyanins in Cultured Cells. Phytochem Anal, 19(6), 479-486. doi: 10.1002/pca.1069.

Fischer, D., Li, Y., Ahlemeyer, B., Krieglstein, J., \& Kissel, T. (2003). In vitro cytotoxicity testing of polycations: influence of polymer structure on cell viability and hemolysis. Biomaterials, 24(7), 1121-1131. doi: 10.1016/S0142-9612(02)00445-3.

Gao, R., Yang, H., Jing, S., Liu, B., Wei, M., He, P., \& Zhang, N. (2018). Protective effect of chlorogenic acid on lipopolysaccharide-induced inflammatory response in dairy mammary epithelial cells. Microb Pathog, 124, 178-182. doi: 10.1016/j.micpath.2018.07.030.

Hudec, J., Burdova, M., Komora, L., Komora, L., Macho, V., Kogan, G., Turianca, I., Kochanova, R., Lozek, O., Haban, M., \& Chlebo, P. (2007). Antioxidant capacity changes and phenolic profile of Echinaccea purpurea, nettle (Urtica dioica L.), and dandelion (Taraxacum officinale) after application of polyamine and phenolic biosynthesis regulators. J Agric Food Chem, 55(14), 5689-5696. doi: 10.1021/jf070777c.

Kitts, D. D., \& Hu, C. (2005). Dandelion (Taraxacum officinale) flower extract suppresses both reaction oxygen species and nitric oxide and prevents lipid oxidation in vitro. Phytomedicine, 12(5), 588-597. doi: 10.1016/j. phymed.2003.12.012.

Ling, Y., \& Xu, Y. (1998). Studies on the chemical constituents of Taraxacum officinale. China J China Mat Med, 23(4), 232-233.
Liang, N., \& Kitts, D. D. (2015). Role of chlorogenic acids in controlling oxidative and inflammatory stress conditions. Nutrients, 8(1), 16. doi: 10.3390/nu8010016.

Liao, J., Zheng, H., Fei, Z., Lu, B., Zheng, H., Li, D., Xiong, X., \& Yi, Y. (2018). Tumor-targeting and $\mathrm{pH}$-responsive nanoparticles from hyaluronic acid for the enhanced delivery of doxorubicin. Int $J$ Biol Macromol, 113, 737-747. doi: 10.1016/j.ijbiomac.2018.03.004.

Liu, M., Chang, Y., Yang, J., You, Y., He, R., Chen, T., \& Zhou, C. (2016). Functionalized halloysite nanotube by chitosan grafting for drug delivery of curcumin to achieve enhanced anticancer efficacy. $J$ Mater Chem B, 4, 2253-2263. doi: 10.1039/C5TB02725J.

Liu, Z., Li, G., Long, C., Xu, J., Cen, J., \& Yang, X. (2018). The antioxidant activity and genotoxicity of isogarcinol. Food Chem, 253, 5-12. doi: 10.1016/j.foodchem.2018.01.074.

Lou, Z., Wang, H., Zhu, S., Ma, C., \& Wang, Z. (2011). Antibacterial activity and mechanism of action of chlorogenic acid. $J$ Food Sci, 76, M398-403. doi: 10.1111/j.1750-3841.2011.02213.x.

Otero-Gonzalez, L., Sierra-Alvarez, R., Boitano, S., \& Field, J. A. (2012). Application and Validation of an Impedance-Based Real Time Cell Analyzer to Measure the Toxicity of Nanoparticles Impacting Human Bronchial Epithelial Cells. Environ Sci Technol, 46, 10271. doi: 10.1021/es301599f.

Rezaei, S. J. T., Sarbaz, L., \& Niknejad, H. (2016). Folatedecorated redox $/ \mathrm{pH}$ dual-responsive degradable prodrug micelles for tumor triggered targeted drug delivery. $R S C A d v, 6$ : 62630-62639. doi: 10.1039/C6RA11824K.

Rui, L., Xie, M., Hu, B., Zhou, L., Saeeduddin, M., \& Zeng, X. (2017). Enhanced solubility and antioxidant activity of chlorogenic acid-chitosan conjugates due to the conjugation of chitosan with chlorogenic acid. Carbohydr Polym, 170, 206216. doi: 10.1016/j.carbpol.2017.04.076.

Schütz, K., Carle, R., \& Schieber, A. (2006). Taraxacum-A review on its phytochemical and pharmacological profile. $J$ Ethnopharmacol, 107, 313-323. doi: 10.1016/j.jep.2006.07.021.

Shi, S., Zhao, Y., Zhang, Y., Huang, K., \& Liu, S. (2008). Phenylpropanoids from Taraxacum mongolicum. Biochem Syst Ecol, 36(9), 716-718. doi: 10.1016/j.bse.2008.06.002.

Sriraman, S.K., Pan, J., Sarisozen, C., Luther, E., \& Torchilin, V. (2016). Enhanced Cytotoxicity of Folic Acid-Targeted Liposomes Co-Loaded with C6 Ceramide and Doxorubicin: In Vitro Evaluation on HeLa, A2780-ADR, and H69-AR Cells. Mol Pharm, 13, 428-437. doi: 10.1021/acs.molpharmaceut.5b00663.

Xu, Z., Shi, X., Jiang, H., Song, Y., Zhang, L., Wang, F., Du, S., \& Chen, J. (2017). A general method to regenerate arrayed gold microelectrodes for label-free cell assay. Anal Biochem, 516, 57-60. doi: 10.1016/j.ab.2016.10.012.

Xu, Z., Song, Y., Jiang, H., Kong, Y., Li, X., Chen, J., \& Wu, Y. (2018). Regeneration of Arrayed Gold Microelectrodes Equipped for a Real Time Cell Analyzer. J Vis Exp, 133, 56250. doi: 10.3791/56250.

Xu, Z., Cai, L., Jiang, H., Wen, Y., Peng, L., Wu, Y., \& Chen, J. (2019). Real-time cell analysis of the cytotoxicity of a pHresponsive drugdelivery matrix based on mesoporous silica materials functionalized with ferrocenecarboxylic acid. Anal Chim Acta, 1051, 138-146. doi: 10.1016/j.aca.2018.11.017.

Yan, Y., Liu, N., Hou, N., Dong, L., \& Li, J. (2017). Chlorogenic acid inhibits hepatocellular carcinoma in vitro and in vivo. $J$ Nutr Biochem, 46, 68-73. doi: 10.1016/j.jnutbio.2017.04.007.

Zhou, S., Guo, P., Li, J., Meng, L., Gao, H., Yuan, X., \& Wu, D. (2018). An electrochemical method for evaluation the cytotoxicity of fluorene on reduced graphene oxide quantum dots modified electrode. Sens Actuators, 255(3), 2595-2600. doi: 10.1016/j.snb.2017.09.066.

Zhu, M., Wong, P. Y., \& Li, R. C. (1999). Effect of Taraxacum officinale on the bioavailability and disposition of ciprofloxacin in rats. J Pharm Sci-us, 88(6), 632-634. doi: 10.1021/js980367q. 